\title{
O USO DO APARELHO AUTOLIGADO NO DIA A DIA DO CONSULTÓRIO -
} REVISÃO DE LITERATURA

\section{THE USE OF SELF-LIGATING BRACKETS IN DAY BY DAY AT ODONTOLOGIC CLINIC}

\author{
Lílian Arévalo Prieto* \\ Everton Flaiban" \\ Daniel Negrete"*.* \\ Denis Clay Lopes dos Santos****
}

\begin{abstract}
RESUMO
Não há como questionar, nos dias de hoje, o aumento da popularidade dos braquetes autoligados. O marketing agressivo dos fabricantes, associado ao tom quase milagroso comentado por bons palestrantes, faz com que o ortodontista, geralmente o menos experiente seja seduzido pelas promessas e tratamentos rápidos, com menos efeitos colaterais e com ganhos monetários maiores do que os tratamentos realizados com braquetes convencionais. Muitas dessas características despertam a curiosidade em compará-los ao sistema convencional. Ao contrário dos braquetes tradicionais, os autoligáveis não necessitam de ligaduras, sejam elásticas ou metálicas. Existe grande disponibilidade de marcas e modelos no mercado inclusive de fabricantes nacionais com preços mais acessíveis. No entanto, na clínica diária, os ortodontistas ainda têm muitas dúvidas com relação a sua eficácia e utilização. Este estudo destina-se em fazer uma revisão de literatura sobre os braquetes autoligados e sua vantagem perante aos braquetes convencionais, auxiliando o ortodontista na eficiência de seus tratamentos ortodônticos.
\end{abstract}

Descritores: Ortodontia • Braquetes ortodônticos

\section{A B S T RACT}

The use of Self- ligating brackets in day by day at odontologic clinic. There is no question, these days, about the increased popularity of self-ligating brackets. The aggressive marketing of the manufacturers, associated with almost miraculous tone commented by good speakers, makes the orthodontist, usually the less experienced, to be seduced by promises of fast treatments with less side effects and gains biggest money than the treatments performed with conventional brackets. Many of these features arouse curiosity in comparing them to conventional system. Unlike traditional braces, self-ligatingdressings need not be elastic or metal. There is a wide availability of brands and models on the market including domestic manufacturers more affordable. However, in clinic, orthodontists still have many questions regarding their effectiveness and use. This study is intended to make a literature review on the self-ligating brackets and their advantage over conventional brackets, helping the orthodontist in the efficiency of his orthodontic treatments.

Descriptors: Orthodontics • Orthodontic brackets

\footnotetext{
* Especialista em Ortodontia, Endodontia e Estomatologia.

*** Mestre em Ortodontia e professor dos cursos de pós-graduação em Ortodontia da Universidade Cruzeiro do Sul.

*** Mestre em Ortodontia e professor dos cursos de pós-graduação em Ortodontia da Universidade Cruzeiro do Sul.

**** Doutorado e Mestrado pela FCM/ Unicamp. PHD em Ortodontia e Ortopedia Facial. PHD em Implantodontia. Coordenador do curso de Odontologia da Universidade Cruzeiro do Sul.
} 


\section{N T R O D U Ç Ã O}

A Ortodontia atual vem sofrendo, há duas décadas, um contínuo processo de adaptação aos novos recursos tecnológicos e às novas técnicas que aparecem com o objetivo de tornar a terapia ortodôntica cada vez mais rápida, confortável e, sobretudo, eficaz para o ortodontista e para o paciente 1 .

Ao contrário do que muitos pensam, os braquetes autoligáveis não constituem uma novidade na Ortodontia. Na metade dos anos 30, o primeiro braquete autoligável foi introduzido na tentativa de meIhorar a eficiência clínica do tratamento ortodôntico ${ }^{2}$. O desenvolvimento de braquetes totalmente programados por Andrews na década de 1970 revolucionou o protocolo da conduta ortodôntica. O manuseio dos arcos ortodônticos se tornou mais simples e mais rápida ${ }^{3}$. O termo "Autoligável", na ortodontia, significa que o braquete, por si, é capaz de fazer a ligadura com o arco de nivelamento por meio de um dispositivo mecânico construído no próprio acessório com a finalidade de fechar a canaleta do braquete. Presume-se, portanto, a capacidade de reduzir o atrito por meio da diminuição da força de ligação do conjunto braquete/fio ${ }^{2}$.

Os braquetes autoligados têm sido apresentados como diferencial para o ortodontista clínico que procura se desdobrar na tentativa de oferecer um tratamento de excelência no menor tempo possível e com número mínimo de consultas. No entanto, a quantidade de informações propiciadas por verdades estabelecidas e não comprovadas a longo prazo cresce a uma velocidade vertiginosa ${ }^{4}$. Entre as afirmações creditadas aos braquetes autoligados estão o menor índice de reabsorções radiculares, a diminuição de extrações e das cirurgias ortognáticas, a não utilização de disjunções palatinas, e o maior conforto dos pacientes. Todavia, infelizmente, não há evidências científicas de qualidade que suportem essas afirmações ${ }^{5}$. Em especial, os aparelhos autoligados, criados inicialmente com o intuito de tornar mais prática a inserção e a remoção do fio ortodôntico da canaleta do braquete, hoje apresentam caraterísticas essenciais para uma abor- dagem mais biológica e mais eficiente da movimentação dentária ${ }^{1}$.

\section{MÉTODOS}

As bases de dados utilizadas na pesquisa da revisão de literatura foram: Pubmed, Medline, Bireme, Scielo, abrangendo periódicos, trabalhos e artigos de âmbito internacional e nacional. A pesquisa limitou-se aos trabalhos publicados até 2015. Priorizaram-se as publicações em línguas inglesa e portuguesa.

\section{REVISÃO DE LITERATURA}

Thorstenson e Kusy ${ }^{6}$ (2001) afirmam que níveis muito baixos de atritos com os aparelhos autoligáveis têm sido claramente demonstrados e quantificados. Há uma grande concordância sobre o fato de os autoligáveis produzirem menor atrito durante a movimentação ortodôntica, quando comparados com os braquetes convencionais. Sabe-se que as ligaduras metálicas produzem entre $30 \%$ e $50 \%$ do atrito promovido por ligaduras elásticas. Estas, quando amarradas em formato de oito, aumentam o atrito entre $70 \%$ e $220 \%$, se comparadas com o formato de O. Portanto, o dispositivo que dispensa o uso dessas ligaduras gera, indiscutivelmente, menores níveis de atrito.

Tecco et al. ${ }^{7}$ (2005) relatam que, nos braquetes ativos, o fechamento se dá por um clipe que invade uma parte da canaleta e uma das paredes. Já no grupo dos braquetes passivos, encontram-se os modelos em que a canaleta do braquete é fechada por meio de uma trava que desliza na superfície externa das aletas, transformando todos os braquetes em tubos e criando paredes nas canaletas, rígidas e passivas. $\mathrm{O}$ atrito nos braquetes passivos é realmente menor, pois o clipe que prende o fio no braquete não tem um contato tão grande com o fio quanto ocorre nos ativos.

Trevisi $^{8}$ (2007) orienta que os braquetes autoligados são indicados para todos os casos de má oclusão, principalmente naqueles de apinhamento severo que necessitam de exodontia de pré-molares e retração inicial de caninos. Nesses casos, o baixo atrito permite a distalização rápida do canino sem que ocorra o movimen-
PRIETO LA

FLAIBAN E

NEGRETE D

SANTOS DCL

O USO DO

APARELHO

AUTOLIGADO NO

DIA A DIA DO

CONSULTÓRIO

REVISÃO DE

LITERATURA

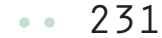

REV, ODONTOL.

UNIV, CID, SÃO

PAULO

$2016 ; 28(3): 230-$

39, SET-DEZ 
PRIETO LA

FLAIBAN E

NEGRETE D :

SANTOS DCL

O USO DO

APARELHO

AUTOLIGADO NO

DIA A DIA DO

CONSULTÓRIO

- REVISÃO DE

LITERATURA

$232 \ldots$

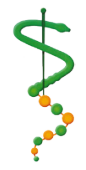

REV. ODONTOL.

UNIV, CID, SÃO:

PAULO

$2016 ; 28(3): 230-$

39, SET-DEZ to vestibular de incisivos.

Kim et al. ${ }^{9}$ (2008) comentam sobre a mais tradicional classificação dos braquetes autoligados, dividindo esse acessório em três tipos, de acordo, com o grau de pressão do sistema aplicado ao fio. Eles podem ser ativos, quando o sistema pressiona o fio dentro da canaleta; passivos, quando o sistema permite liberdade do fio na canaleta; ou interativos, quando os braquetes autoligados exercem pressão em fios mais espessos, mas permitem liberdade de fios menos calibrosos. Quando o sistema de braquetes ativo é utilizado, o atrito é muito maior do que quando se utiliza o sistema de braquetes passivos.

Para Harradine ${ }^{10}$ (2008), contrariamente aos que muitos pensam, os braquetes autoligados não representam um desenvolvimento recente e revolucionário, pois, desde 1935, Russel descreveu na literatura que o uso de amarrilhos para fixação do arco era dispensável na ortodontia. Nesse sistema, o arco era fixado e pressionado dentro da canaleta dos braquetes Edgewise por um parafuso. Sendo assim, há mais de 70 anos, esse conceito já fazia parte do arsenal ortodôntico, mas, em função do alto custo e fragilidade das peças devido às limitações de fabricação, não se popularizou como provavelmente mereceria. Somente em 1972, surgiu outro dispositivo, idealizado por Wildman e chamado de Edgelok, que apresentava uma tampa por vestibular para fechar a canaleta do braquete.

Berger $^{11}$ (2008) relata que, na década de 80, novos sistemas surgiram. O Mobil-lock precisava de instrumento rotatório para abrir e fechar a canaleta, porém, assim como o Edgelok, esse sistema apresentava um controle de rotação muito pobre. O Speed (Canada, Industries) com um design mais estético, significativamente menor e, consequentemente, com distância interbraquetes maior, apresentava uma redução no acúmulo de alimentos e uma propaganda mais forte de que esse braquete causaria menor atrito durante a movimentação ortodôntica. Esse sistema se diferenciava dos anteriores por apresentar uma tampa que deslizava no sentido vertical para o fechamento da canaleta. A característica ímpar dessa tampa é ter sido confeccionada, originalmente, com aço inoxidável e, hoje em dia, ela apresenta uma liga de níquel titânio fina e resiliente, que a torna extremamente flexível. Salienta-se, também, a facilidade de fechamento das tampas dos braquetes, ocasionando redução do tempo de até quatro vezes em relação aos sistemas convencionais com elásticos.

Harradine $^{10}$ (2008), na década de 90, sugeriu o braquete Time (Alemanha) que se assemelhava ao Speed na aparência e na maneira ativa de atuação. Em seguida a American Orthodontics (EUA) lançou o braquete com tampa ativa chamado Sigma, concomitantemente com o lançamento dos sistemas passivos Damon System (EUA), o Damon SLI, e mais tarde, em 1999, o Damon SLII. Ambos apresentam uma tampa lisa e retangular que desliza entre as aletas. A justificativa desses novos sistemas era que seu desenho permitiria um rápido nivelamento, devido ao fato de os dentes deslizarem por um caminho de pouca, ou nenhuma, fricção entre o braquete e a canaleta. No sistema Damon SLI havia muitas quebras da trava deslizante, já no sistema Damon SLII houve uma melhora nessa imperfeição, diminuindo o número de quebras. A Company lançou, em 1998, mais um braquete passivo, chamado Twin-lock, semelhante ao Edgewise geminado, porém com tampa que se move no sentido oclusal com o auxílio de um instrumento universal.

Birnie $^{12}$ (2008) comenta em seu trabaIho que o Sistema Damon em 2006 lança o Damon MX, o qual dividia o tratamento em quatro fases. Também o surgimento de um autoligado ativo chamado In-Ovation C (EUA). A Forestadent (Alemanha) apresentou o aparelho autoligado ativo chamado Quick, com base microrretentiva e menos volumoso; e por último a $3 \mathrm{M}$ Unitek (EUA), com a inovação do sistema autoligado, apresentando o Smartclip. Este apresenta o formato romboide e com ângulo inserido na forma de braquete, o que favorece o seu posicionamento, pois o profissional pode usar as bordas incisais como referência na face vestibular dos dentes.

Macedo $^{13}$ (2008) relata que, para os ca- 
sos em que o fio retangular é empregado por mais tempo e a mecânica de deslize é necessária, como por exemplo os casos com extração, os braquetes passivos são mais recomendados. Isso quando a capacidade de leitura do torque é necessária. Acredita-se que o braquete passivo tem a função de manter o fio no interior da canaleta evitando a interação do fio e do braquete. Os braquetes autoligáveis apresentam baixo atrito, mas vários aspectos quanto à escolha entre um ou outro modelo, inclusive preço, qualidade, facilidade de obtenção e vantagens clínicas devem ser consideradas.

$\operatorname{Nader}^{14}$ (2008) orienta que os aparelhos autoligáveis são mais indicados nos casos de apinhamento tratados sem extração dentária, pois, nesses casos, o baixo atrito vai promover a resolução do apinhamento com tempo menor de tratamento.

Maltagliati ${ }^{15}$ (2007) comenta também sobre uma desvantagem dos braquetes autoligados passivos pois eles podem obstruir o controle do torque na fase de finalização e, por isso, um amarrilho pode ser necessário para aumentar a fricção entre o braquete e o fio.

Maltagliati et al. ${ }^{16}$ em 2013 dizem que podemos comprovar cientificamente, que, com uso dos autoligados, há um aumento significativo das dimensões transversais dos arcos dentários, quando comparado com o aumento da profundidade do arco que ocorre após a fase de nivelamento e alinhamento. Esse comportamento diferencial do sistema autoligado em relação à mecânica convencional parece estar relacionado, sim, ao baixo atrito, mas não sem considerar o fio de níquel titânio termoativado de baixo calibre como coadjuvante no resultado. Além dos resultados científicos, podemos constatar, clinicamente, as mudanças na forma como o alinhamento e nivelamento ocorrem. Castro ${ }^{4}$ (2009), no início do século XXI, sugeriu a Oyster (Suécia), o primeiro sistema autoligado estético, feito de fibra de vidro reforçada por um polímero, dando transparência ao braquete. A tampa fecha sobre a canaleta no sentido cérvico-oclusal, funcionando de forma ativa, porém, caso se queira, pode-se removê-la e o braquete funciona como um sistema tradicional, sendo necessária a utilização de amarriIhos metálicos ou elásticos para manter o fio dentro da canaleta. Em 2004, surgiu o Damon III, considerado semiestético, com um mecanismo fácil e seguro para abertura e fechamento da trava; entretanto, ele apresentava três problemas significativos: descolagem frequente, separação do metal com a porcelana e fratura da aleta. Ressalta-se, ainda, que, se um paciente almeja um braquete estético associado à ligadura estética também aceitável, a escolha do Damon III não seria a melhor opção.

Maltagliati et al. ${ }^{16}$ (2013), em seu trabalho, relatam que, com a crescente utilização de braquetes autoligados, alguns ortodontistas têm suscitado a possibilidade de simplificar essa parte de preparo prévio, pois o tratamento, com baixa fricção, proporcionaria uma adaptação transversal posterior que impediria os efeitos colaterais importantes do nivelamento, possibilitando o tratamento de casos com apinhamento, sem a prévia obtenção de espaço. Obviamente que o caso deve estar muito bem indicado, pois o tratamento de apinhamentos sem a prévia obtenção de espaço, como extrações ou desgastes, deve estar embasado em um diagnóstico criterioso e voltado para o tratamento de casos com características vantajosas para a obtenção de arcos dentários mais amplos e expandidos, como no caso de pacientes com corredor bucal amplo, dentes com inclinação lingual da coroa, sobremordida profunda, de padrão com altura facial anterior inferior diminuída; caso contrário, os efeitos de mecânica tornam o resultado comprometedor e ampliam o tempo de tratamento necessário para corrigir o que foi alterado com o tratamento.

Maltagliati et al. ${ }^{16}$ (2013) comentam em seu trabalho sobre os fios que temos disponíveis no mercado, e o que mais contempla essas características é liga níquel titânio termoativa. Embora a composição da liga não seja a de melhor performance no quesito atrito, perdendo para os fios de aço inoxidável, entretanto, a alta flexibilidade da liga e o baixo patamar de força que atinge mesmo em situações de grande deflexão suplantam a característica de maior atrito, quando comparado com
PRIETO LA

FLAIBAN E

NEGRETE D

SANTOS DCL

O USO DO

APARELHO

AUTOLIGADO NO

DIA A DIA DO

CONSULTÓRIO

REVISÃO DE

LITERATURA

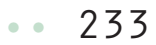

REV, ODONTOL.

UNIV, CID, SÃO

PAULO

$2016 ; 28(3): 230-$

39, SET-DEZ 
PRIETO LA

FLAIBAN E

NEGRETE D

SANTOS DCL

O USO DO

APARELHO

AUTOLIGADO NO

DIA A DIA DO

CONSULTÓRIO

REVISÃO DE

LITERATURA

\section{$234 \ldots$}

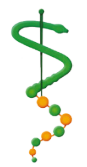

REV. ODONTOL.

UNIV, CID, SÃO

PAULO

2016; 28(3): 230-

39, SET-DEZ fios de aço. Além disso, essa liga possui a propriedade memória de forma, importantíssima para a manutenção da ativação do fio, não perdendo em eficiência de movimentação diante das deflexões que sofre ao ser posicionado no arco. Os fios de níquel titânio termoativados estão disponíveis em vários calibres, porém, como mencionados anteriormente, para iniciar o tratamento tirando o máximo proveito dos braquetes, é importante que o fio seja de pequeno calibre. Quanto menor o diâmetro melhor, principalmente nos casos de apinhamentos.

Nóbrega $^{17}$ (2010), em seu trabalho, comenta sobre o atrito estático que constitui a força necessária para iniciar o movimento de um corpo que, em Ortodontia, representa força mínima necessária para que o dente inicie seu movimento. Acredita-se que, quanto mais mal posicionado estiver o dente, maior a deflexão do fio e, portanto, o contato deste com o braquete aumenta o atrito estático e a força necessária para o movimento. O atrito estático ocorre quando há contato entre duas superfícies, mas não há movimento de um corpo sobre o outro; a partir da hora em que a força aplicada com o intuito de promover deslocamento supera o coeficiente de atrito estático, inicia-se o movimento.

Sathler et al. ${ }^{18}$ (2011) relatam sobre alguns exemplos de braquetes do sistema ativo: In-Ovation R, Speed e Time. Dentre os exemplos de braquetes do grupo passivo podemos citar o Damon e SmartClip. Outra classificação, mais atual, divide os autoligados em apenas dois grupos, de acordo com o tipo de sistema de fechamento da canaleta: braquetes autoligáveis com parede ativa (spring clip) e os autoligáveis com parede passiva (passive slide).

Zanelato et al. ${ }^{19}$ (2013) comentam em seu artigo que, nos aparelhos que são usados ligaduras elásticas, a aplicação da força biomecânica deve, primeiramente, quebrar a resistência provocada pela ligadura, para, em seguida, promover a movimentação dentária. Tal fato faz com que os níveis de força necessária sejam mais elevados, podendo ser vantagem a utilização de aparelhos autoligados passivos, já que sua utilização elimina o atrito provo- cado pelas amarras das ligaduras, permitindo diminuir os níveis de força aplicados nas biomecânicas. Para a execução de tratamentos mais tranquilos, o ortodontista deve identificar onde estão ocorrendo movimentações, e eliminar as possíveis resistências. Quando há problema, deve-se diminuir a resistência ao deslize, não aumentar a força da biomecânica.

Normando $^{2}$ (2015) comenta que dois tipos de braquetes autoligados foram desenvolvidos. Os braquetes denominados passivos são aqueles que possuem um clip que somente fecha a canaleta, transformando o braquete em um tubo, portanto, não exercendo pressão direta sobre o fio. No outro sistema, denominado ativo, o clip funciona como uma mola, que pressiona o arco e, dessa forma, esse tipo de braquete não pode ser considerado um elemento passivo da mecânica ortodôntica.

Martins $^{5}$ (2015) relata que o atrito ajuda a alinhar os dentes quando há falta de espaço. A resistência ao deslizamento causada pelas forças que produzem o travamento elástico do fio, ou binding, nos casos com moderada irregularidade inicial, produz os espaços necessários para a correção de rotações e inclinações dos dentes. O pensamento de que esse travamento, que impede o fio de deslizar, impediria o funcionamento do aparelho ortodôntico não condiz com a realidade, já que ele não impede um fio de níquel- titânio, por exemplo, de querer retornar ao seu formato original.

\section{I S CUSSÃO}

Segundo Chen et al. ${ }^{20}$, em 2010, não foi comprovada uma maior eficiência do tratamento ortodôntico com braquetes autoligáveis. Assim, à luz da ciência atual, não parece ser razoável propor ao paciente um tratamento com braquetes autoligáveis com a finalidade de reduzir o tempo de tratamento. Contudo, para Fleming e Johal ${ }^{21}$, em 2010, as revisões sistemáticas de estudos clínicos vêm, rotineiramente, pulverizando a maioria das vantagens divulgadas pela indústria de materiais ortodônticos. Assim, ainda não foi comprovada a existência de um nível menor de dor, durante o alinhamento e nivelamen- 
to ortodôntico, quando usados braquetes autoligáveis, comparados aos sistemas convencionais. Também não há comprovação de que esses braquetes reduzam o risco de reabsorção radicular, doenças periodontais por uma maior colonização bacteriana, ou a descolagem de braquetes durante o tratamento ortodôntico. As pesquisas clínicas e experimentais documentaram que os aparelhos autoligados, ativos ou passivos, possuem menor resistência friccional quando comparados aos convencionais ligados por elastômeros ou amarrilhos metálicos. Tais pesquisas foram feitas comparando várias marcas de braquetes autoligados ativos com braquetes autoligados passivos e, também, comparando os sistemas autoligado e convencional de amarração ${ }^{22}$. Mas Jacobson $^{23}$, em 2007, diz que a superioridade dos sistemas autoligados em relação aos sistemas convencionais vem sendo descrita desde 1992 e corroborada por diversos autores no decorrer dos anos seguintes. Ele acredita que a propriedade de redução da força superficial do atrito não é uma característica exclusiva do design do braquete e que os tipos de ligas metálicas dos fios ortodônticos utilizados em pesquisas, bem como o grau de deflexão desses fios, estariam mais relacionados com a diminuição da fricção do que com a presença ou não de ligaduras convencionais.

Berger $^{24}$, em 2000, também relata a alta aceitação por parte dos pacientes dos sistemas autoligados. Questionados sobre os aspectos do tratamento, ao finalizarem, relataram a qualidade nos resultados, tempo de tratamento, espaçamento entre as consultas e conforto. Porém, Castro $^{4}$, em 2009, afirma que os braquetes autoligados ainda não demonstraram superioridade mecânica em relação aos sistemas convencionais, de forma a justificar seu maior custo. Além disso, a maioria das informações com relação aos sistemas autoligados deriva de material promocional das empresas, relatos de casos e congressos. Araújo ${ }^{25}$, em 2008, em seu trabalho, relata um importante questionamento levantado sobre a credibilidade em relação à prescrição do fabricante. Considerando-se que, ao início do tratamento, escolhemos as prescrições de acordo com o fabricante, em contrapartida, a utilização de fios de aço retangulares ao final do tratamento pode não levar às inclinações desejadas.

Ressalta-se, também, a importância da avaliação do padrão facial do paciente no momento do diagnóstico, pois não há prescrição e nem sistema de braquetes autoligados que compense um padrão facial determinado geneticamente como desfavorável. Secundariamente, o profissional escolhe a técnica (Edgewise ou Straight Wire), prescrição do braquete, tipo (metálico ou estético) e o sistema (autoligado ou convencional), de acordo com a sua preferência pessoal e de cada paciente. Já Martins $^{5}$, em 2015, relata em seu trabalho que, em um grande número de estudos clínicos, os braquetes autoligados não alinham os dentes mais rapidamente do que os braquetes convencionais, e que, talvez, até demorem um pouco mais. Relata, também, que os braquetes autoligados parecem estar significativamente associados a um tratamento, em média, dois meses mais longo, com um mínimo de aumento na distância intercaninos e com um mínimo de aumento na distância intermolares.

E, também, Marshall et al. ${ }^{26}$ em 2010, relatam que a própria comissão para assuntos científicos da Associação Americana de Ortodontia avaliou algumas vantagens atribuídas aos braquetes autoligados, e concluiu que não há evidência científica que aponte para um alinhamento mais rápido em comparação com os braquetes convencionais. Mas Zanelato et al. ${ }^{19}$, em 2013, relatam que na tentativa de eliminar o atrito provocado pelas ligaduras que estabelecem as amarrações dos fios nos braquetes, tornando a biomecânica de deslize mais eficiente, foram desenvolvidos os aparelhos autoligados passivos. Essa classificação dá-se quando o sistema de fechamento da canaleta dos braquetes não contata o fio ortodôntico. Nos aparelhos autoligados passivos, o atrito das amarrações é praticamente inexistente. Com isso, o tempo de tratamento ortodôntico com aparelho fixo pode ser reduzido, e os níveis de força diminuídos.

Maltagliati et al. ${ }^{16}$, em 2013, dizem num artigo que todo braquete autoligado, seja ele ativo ou passivo, apresenta a
PRIETO LA

FLAIBAN E

NEGRETE D

SANTOS DCL

O USO DO

APARELHO

AUTOLIGADO NO

DIA A DIA DO

CONSULTÓRIO

REVISÃO DE

LI TERATURA
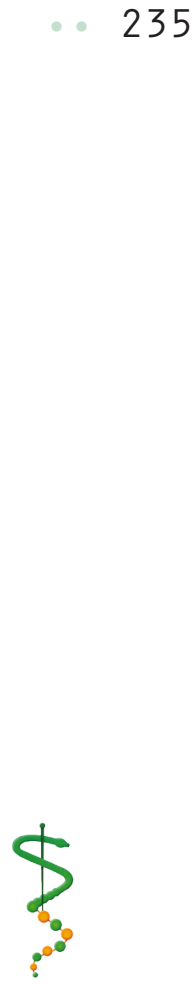

REV, ODONTOL.

UNIV, CID, SÃO

PAULO

$2016 ; 28(3): 230-$

39, SET-DEZ 
PRIETO LA

FLAIBAN E

NEGRETE D :

SANTOS DCL

O USO DO

APARELHO

AUTOLIGADO NO

DIA A DIA DO

CONSULTÓRIO

- REVISÃO DE

LITERATURA

$236 \ldots$

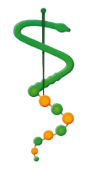

REV, ODONTOL.

UNIV, CID, SÃO

PAULO

2016; 28(3): $230-$

39, SET-DEZ quarta parede móvel, utilizada para converter o slot em tubo. No grupo de braquetes passivos, encontram-se os modelos em que a canaleta do braquete é fechada por meio de uma trava que desliza na superfície externa das aletas, transformando todos os braquetes em tubos e criando quatro paredes nas canaletas, rígidas e passivas. No grupo dos braquetes ativos, o fechamento se dá por um clipe que invade uma parte da canaleta, em uma das paredes, superior ou inferior. Esses clipes têm a característica de exercer certa pressão sobre os fios mais calibrosos, normalmente superiores ao 0,018. "Existe, ainda, um terceiro tipo, com clipes posicionados nas laterais de um braquete com design convencional, desenvolvido pela empresa $3 \mathrm{M}$, mas que se enquadra no grupo dos passivos, pela sua característica de atuação. Já Read et al. ${ }^{27}$, em 1997, simularam, em laboratório, as angulações geradas pelo mau posicionamento dentário e verificaram que o aumento do atrito acontecia em todos os braquetes, convencionais, passivos e ativos. Concluíram que, quando o alinhamento é substancial, o braquete autoligado passivo se comporta melhor do que aqueles com clips. Porém, conforme a má oclusão se torna prevalente e o calibre do fio diminui, os tipos de braquetes autoligados ativos e passivos perdem distinção. Portanto, os braquetes ativos e passivos têm performance parecida no primeiro estágio do tratamento e tendem a ser diferentes com o alinhamento e com fios mais calibrosos, o que significa que, para tratamento sem extração, a forma de travamento do fio no braquete parece perder importância.

Maltagliati et al. ${ }^{16}$, em 2013, relatam que, no final do tratamento, quando se necessita de mecânica de fechamento de espaços, é preciso aliar baixo atrito com controle de torque. É interessante observar que o que diferencia o sistema convencional do autoligado, nesse momento, é o braquete do segundo pré-molar apenas, já que os tubos de molares são, em essência, braquetes autoligados. Se considerar-se que, em comparação ao sistema convencional, os autoligados reduzem o atrito, mesmo os do tipo ativo, e que somente o braquete do segundo pré-molar ofereceria alguma influência, não parece haver, também, nesse momento, diferença significativa sobre o modelo de braquete utilizado. Nem diferença no tempo de retração anterior entre braquetes autoligados e os convencionais. Entretanto, no controle de torque, quando este é necessário, os modelos ativos parecem ser mais vantajosos. Já de acordo com Harradine ${ }^{28}$, em 2001, o uso dos autoligáveis reduz em média 4 meses do tempo de tratamento, diminui em 24 segundos a colocação e a remoção do fio por arcada, e abrevia em média 4 visitas por tratamento. A habilidade de assegurar um completo e seguro encaixe do arco na canaleta dos braquetes autoligáveis, concomitantemente ao uso de arcos de alta tecnologia, faz do aumento dos intervalos entre as consultas uma etapa possível. Outro benefício desse encaixe completo do arco na canaleta do braquete é que a parede, seja ativa ou passiva, promove fechamento completo do arco no interior da canaleta, o que permite maior controle de rotação. Mas, como relatam Zanelato et al. ${ }^{19}$ em 2013, na fase biomecânica, dentes mal posicionados, girados, em apinhamento ou desnivelados podem, também, provocar atrito. Manter níveis baixos de atrito durante a execução da biomecânica de deslize é um desafio ao ortodontista. Níveis altos de resistência à movimentação podem acarretar, principalmente, movimentos mais lentos. Quando esse fato acontece, um erro comum é aumentar a quantidade de força empregada. Quando há excesso de força, componentes indesejados podem influenciar negativamente no tratamento. O profissional passa a ter de se preocupar mais com o controle de torque dos incisivos, com o aprofundamento da mordida e com a perda de ancoragem.

Sathier et al. ${ }^{18}$, em 2011, afirmam que os braquetes autoligados passivos produzem menor resistência friccional. Entretanto, esse menor grau de atrito pode resultar em uma maior perda de controle de torque. Os braquetes Damon, no início do tratamento foram menos dolorosos, devido aos fios menos calibrosos, mas substantivamente mais dolorosos que com os convencionais, quando o segundo fio for inserido, devido à menor liberdade deste 
na canaleta. Porém, Martins ${ }^{5}$, em 2015, relata que, nos casos onde existem espaços suficientes para o alinhamento, isso é, quando há diastemas entre dentes inclinados e rotados, um baixo atrito auxiliaria o alinhamento, sem que mais espaços fossem abertos. Nesse caso, um baixo atrito não quer dizer que a correção do apinhamento seria mais rápida, mas, sim, que seria mais eficiente, pois esses espaços não precisariam ser fechados após o alinhamento. Nessas situações, o clínico deve tentar diminuir ao máximo o travamento do fio, utilizando fios flexíveis, de baixo calibre em relação ao slot do braquete, evitando grandes angulações entre o fio e o braquete. Mas, para Zanelato et al. ${ }^{19}$, em 2013, a essência que torna possível a execução da biomecânica de deslize é a perfeita interação dos arcos ortodônticos com as canaletas dos braquetes. Tal fato permite o movimento livre dos dentes em todas as fases do tratamento. O nível de atrito deve ser mantido baixo, sempre que necessário. Dessa forma, níveis de forças mais baixos podem ser empregados, beneficiando, principalmente, os principais interessados nesse tema: os pacientes.

Segundo Maltagliati ${ }^{29}$, em 2006, quando conseguimos estabelecer liberdade entre fio e canaleta, o dente deslizará sobre o mesmo e, ainda que esteja em fio de baixo calibre, a deflexão do fio somente ocorrerá quando a angulação do dente em direção ao tracionamento ocorrer e tocar o fio em ângulos opostos, fazendo com que os efeitos colaterais sejam menos sentidos. E, em fios mais calibrosos, apesar de aumentar o atrito, o deslize estará facilitado não necessitando do aumento excessivo da força para produzir movimento, o que protege os dentes de ancoragem. E é isso que ocorre com a utilização de braquetes autoligados. Já Bernie, em 2008, demonstrou que aparelhos autoligados passivos utilizam menos ancoragem que os aparelhos convencionais. Isso é confirmado pela afirmação de profissionais que utilizam o sistema autoligado com menos dispositivos de ancoragem. Para Peck ${ }^{30}$, em 2008, a quantidade de expansão transversal que pode ocorrer nestes tem levantado algumas dúvidas, devido ao risco de induzir danos iatrogênicos aos tecidos periodontais na forma de recessões gengivais e deiscências na cortical óssea que poderiam, em longo prazo, comprometer o prognóstico do tratamento. Já para Lenza $^{31}$, 2008, os resultados demonstram haver redução na quantidade de osso alveolar por vestibular após o tratamento, embora em nenhum caso tenham sido observadas deiscências ósseas. A quantidade de expansão mais acentuada foi detectada na região de pré-molares, seguida por caninos, e em menor magnitude nos molares. Embora esses resultados pareçam promissores quanto ao uso do sistema autoligado, ressalta-se que foram tratados apenas adolescentes com má oclusão de classe I e II, com moderado grau de apinhamento.

Maltagliati ${ }^{15}$, em 2007, indica que os braquetes autoligáveis passivos apresentam baixos níveis de atrito obstruindo o controle de torque na fase de finalização e, por isso, pode ser necessário um amarrilho para aumentar a fricção entre o braquete e o fio. E Jakob ${ }^{32}$, em 2008, relata que os braquetes autoligáveis ativos apresentam flexibilidade do clipe, o que minimiza os efeitos deletérios das forças pesadas, pois o clipe dissipa parte da força aplicada e auxilia o fio ortodôntico em alguns dos movimentos dentários principais, especialmente os de angulação, rotação e torque. Por isso, o movimento é obtido com maior eficiência usando-se forças moderadas. Contudo, para Eliades e Pandis ${ }^{33}$, em 2011, o braquete autoligável ativo apresenta muita eficiência no que diz respeito ao controle do torque, porque esses braquetes conseguem captar a expressão de torque contida nos braquetes com fios retangulares finos e, portanto, com intensidade menor de força.

\section{CONCLUSÃO}

Embora os aparelhos autoligados possam ter grande impacto na Ortodontia, devemos estar cientes quanto às suas reais vantagens, considerando todos os fatores inerentes à sua mecânica de atuação. Uma odontologia de evidências deve sempre prevalecer.

As vantagens demonstradas pelos braquetes autoligados em relação aos convencionais explicam-se, em princípio,
PRIETO LA

FLAIBAN E

NEgRETE D

SANTOS DCL

O USO DO

APARELHO

AUTOLIGADO NO

DIA A DIA DO

CONSULTÓRIO

REVISÃO DE

LITERATURA

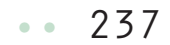

REV, ODONTOL.

UNIV, CID, SÃO

PAULO

$2016 ; 28(3): 230-$

39, SET-DEZ 
PRIETO LA

FLAIBAN E

NEGRETE D

SANTOS DCL

O USO DO

APARELHO

AUTOLIGADO NO

DIA A DIA DO

CONSULTÓRIO

- REVISÃo DE

LITERATURA

238

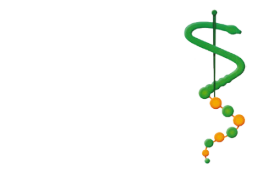

REV. ODONTOL.

UNIV, CID, SÃO

PAULO

2016; 28(3): 230-

39, SET-DEZ
I SSN 1983-5183

porque todos os autoligados, apesar de o modo como são demonstrados na prática possa diferir, eles apresentam maior certeza na inserção total do arco no slot, pouco atrito entre o braquete e o arco, menor tempo de cadeira e maior rapidez na mu-

\section{REFERÊNCIAS}

1. Carvalho GD, Perdigão HV, Neves LS, Carvalho AB, Carvalho EMD. Análise comparativa entre os sistemas convencionais e autoligado Ortodontia 2011 jul-ago;44(4):376-80.

2. Normando D. Braquetes autoligáveis: por que sim, por que não? Rev clín ortodon Dental Press 2015 dez-jan;13(6):20-7.

3. Maltagliati L. Sistema autoligado: quebrando paradigmas. . Ortodontia SPO 2009 42(5):360-1.

4. Castro R. Braquetes autoligados: eficiência x evidências científicas. Rev Dent Press Ortodon Ortop Facial 2009 ago; 14(4):20-4.

5. Martins RP. Braquetes autoligáveis alinham os dentes mais rapidamente? Rev Clín Orthod Dental Press 2015 jan;13(6):10-5.

6. Thorstenson GA, Kusy RP. Resistance to sliding of self-ligating brackets versus conventional stainless steel twin brackets with second-order angulation in the dry and wet (saliva) states. Am J Orthod Dentofacial Orthop 2001 Oct; 120(4):361-70.

7. Tecco S, Festa F, Caputi S, Traini T, Di Iorio D, D'attilio M. Friction of conventional and self-ligating brackets using a 10 bracket model. The Angle orthodontist 2005 Nov;75(6):1041-5.

8. Trevisi HJ. SmartClip: tratamento ortodôntico com sistema de aparelho autoligado: conceito e biomecânica. Rio de Janeiro: Elsevier; 2007. dança do arco.

Deve-se ter em mente que os autoligados são apenas mais uma ferramenta de uso para o ortodontista e a certeza de que eles vieram para ficar.

9. Kim TK, Kim KD, Baek SH. Comparison of frictional forces during the initial leveling stage in various combinations of self-ligating brackets and archwires with a custom-designed typodont system. Am J Orthod Dentofacial Orthop 2008 Feb;133(2):187.e15-24.

10. Harradine N. The history and development of self-ligating brackets. Semin Orthod 2008 14(1):5-18.

11. Berger JL. The Speed System: an overview of the appliance and clinical performance. Seminars in Orthodontics 2008 14(1):54-63.

12. Birnie D. The damon passive self-ligating appliance system. Semin Orthod 2008 14(1):19-35.

13. Macedo A. Tratamento ortodôntico com braquetes autoligáveis. Ortodontia SPO 2008 4(1):324-9.

14. Nader R. Tratamento ortodôntico com braquetes autoligáveis. Ortodontia SPO 2008 4(1):1-5.

15. Maltagliati LÁ. Autoligáveis no que diferem? Qual a vantagem em utilizar braquetes autoligáveis na prática clinica? . Rev Clín Ortodon Dental Press, Maringá 2007 out/nov;6(5):17-32.

16. Maltagliati LA, Myiahira YI, Fattori L, Capelozza Filho L, Cardoso M. Alterações transversais dos arcos dentários de pacientes tratados sem extração com braquetes autoligáveis. Dental Press J Orthod 2013 maio-jun;18(3):39-45.

17. Nóbrega C. Ortodontia autoligante interativa. São Paulo: Profile; 2010.

18. Sathler R, Silva RG, Janson G, Branco NCC, Zanda M. Desmistificando os braquetes autoligáveis. Dental Press J Orthod 2011 abr;16(2):e1-e8. 
19. Zanelato AT, Zanelato ACT, Zanelato RCT. Mudança de paradigmas na utilização de forças em Ortodontia com o uso de aparelhos autoligados. Rev Ortodontia SPO 2013 46(3):269-74.

20. Chen SS, Greenlee GM, Kim JE, Smith CL, Huang GJ. Systematic review of self-ligating brackets. Am J Orthod Dentofacial Orthop 2010 Jun;137(6):726.e1-.e18; discussion -7.

21. Fleming PS, Johal A. Self-ligating brackets in orthodontics. A systematic review. The Angle orthodontist 2010 May;80(3):575-84.

22. Rinchuse DJ, Miles PG. Self-ligating brackets: present and future. $A m$ J Orthod Dentofacial Orthop 2007 Aug;132(2):216-22.

23. Jacobson A. The effect of extraneous forces upon the frictional characteristics of self-ligating orthodontic brackets and nickel-titanium archwires utilizing a novel in-vitro model, David M. Bunkall, Saint Louis University, St Louis, Mo. American Journal of Orthodontics and Dentofacial Orthopedics 2007 8//;132(2):268.

24. Berger JL. Self-ligation in the year 2000. J Clin Orthod 2000 34(2):74-81.

25. Araujo CCM. Avaliação das inclinações dentárias obtidas no tratamento ortodôntico com braquetes autoligáveis utilizando tomografia computadorizada. [Mestrado]. São Paulo: Universidade Metodista de São Paulo; 2008.
26. Marshall SD, Currier GF, Hatch NE, Huang GJ, Nah HD, Owens SE, et al. Ask us. Self-ligating bracket claims. Am J Orthod Dentofacial Orthop 2010 Aug;138(2):128-31.

27. Read-Ward GE, Jones SP, Davies EH. A comparison of self-ligating and conventional orthodontic bracket systems. British journal of orthodontics 1997 Nov;24(4):309-17.

28. Harradine NW. Self-ligating brackets and treatment efficiency. Clinical orthodontics and research 2001 Nov;4(4):220-7.

29. Maltagliati LA. Autoligados na mecânica Straight Wire. In: Lindoso, GB. Atualidades em ortodontia e odontopediatria. 2. ed. Recife: Universidade Federal de Pernambuco; 2006. p. 67 77.

30. Peck S. So what's new? Arch expansion, again. The Angle orthodontist 2008 May;78(3):574-5.

31. Lenza MA. Braquetes autoligáveis: futuro da Ortodontia? Rev Dent Press Ortodon Ortop Facial 2008 dez;13(6):17-9.

32. Jakob SR. Braquetes autoligáveis interativos x passivos: nova visão em ortodontia e ortopedia funcional dos maxilares. 16. ed. São Paulo: Santos; 2008.

33. Eliades T, Pandis N. Autoligáveis em ortodontia. São Paulo: Napoleão; 2011.

Recebido em 29/06/2016

Aceito em 01/12/2016
PRIETO LA

FLAIBAN E

NEGRETE D

SANTOS DCL

O USO DO

APARELHO

AUTOLIGADO NO

DIA A DIA DO

CONSULTÓRIO

- REVISÃo de

LITERATURA

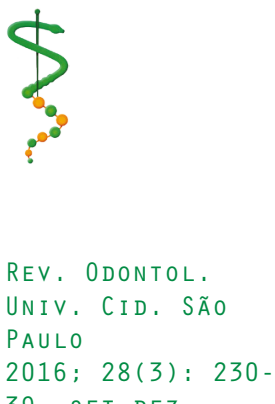

39, SET-DEZ 